\title{
Project Sanitarium: playing tuberculosis to its end game
}

\author{
Iain Donald ${ }^{1}$ (D) Karen A. Meyer ${ }^{1} \cdot$ John Brengman $^{1} \cdot$ \\ Stephen H. Gillespie ${ }^{2} \cdot$ Ruth Bowness $^{2}$
}

(C) The Author(s) 2017. This article is an open access publication

\begin{abstract}
Interdisciplinary and collaborative projects between industry and academia provide exceptional opportunities for learning. Project Sanitarium is a serious game for Windows PC and Tablet which aims to embed learning about tuberculosis (TB) through the player taking on the role of a doctor and solving cases across the globe. The project developed as a collaboration between staff and undergraduate students at the School of Arts, Media and Computer Games at Abertay University working with academics and researchers from the Infection Group at the University of St Andrews. The project also engaged industry partners Microsoft and DeltaDNA. The project aimed to educate students through a workplace simulation pedagogical model, encourage public engagement at events and through news coverage and lastly to prototype whether games could be used to simulate a virtual clinical trial. The project was embedded in the Abertay undergraduate programme where students are presented with real world problems to solve through design and technology. The result was a serious game prototype that utilized game design techniques and technology to demystify and educate players about the diagnosis and treatment of one of the world's oldest and deadliest diseases, TB. Project Sanitarium
\end{abstract}

The original version of this article was revised: the article note "John Brengman—-deceased" was deleted.

Iain Donald

i.donald@abertay.ac.uk

Karen A. Meyer

k.meyer@abertay.ac.uk

Stephen H. Gillespie

shg3@st-andrews.ac.uk

Ruth Bowness

rec9@st-andrews.ac.uk

1 School of Arts, Media and Computer Games, Abertay University, Dundee, UK

2 School of Medicine, University of St Andrews, St Andrews, UK 
aims to not only educate the player, but allows the player to become a part of a simulated drug trial that could potentially help create new treatments in the fight against TB. The game incorporates a mathematical model that is based on data from real-world drug trials. The interdisciplinary pedagogical model provides undergraduates with workplace simulation, wider industry collaboration and access to academic expertise to solve challenging and complex problems.

Keywords Serious games - Games with purpose - Games for change - Games education - Educational games - Interdisciplinary working - Collaborative research

Games together with the processes and technologies used to develop them have changed the way that we all interact with serious and complex topics. As games have become more advanced, immersive and engaging their evolution has been rewarded with wider audiences and ever-expanding genres. Over recent years, games developed in the commercial sector have increasingly presented serious topics and some have met with considerable commercial success. Although 'serious games' are not particularly new or novel they have increasingly become more entertaining. Games are now utilized to teach, train and raise awareness of complex and multifaceted issues across a wide range of fields and disciplines.

Creating games is a fundamentally collaborative experience and has direct benefits for students, researchers and academics across partnering institutions. Arguably the serious game creation process not only encourages cooperation across institutions and disciplines, but facilitates peer-to-peer learning and fosters better academic-industry relationships. Project Sanitarium is a game created by collaboration between students and academics from Abertay University's School of Arts, Media and Computer Games (AMG) and the Infection Group at the University of St Andrews School of Medicine. It is a 'serious game' designed to use real world medical data regarding the treatment of Tuberculosis (TB) and combine it with proven game mechanics to deliver a simulation that could entertain players, mimic clinical trials and provide a powerful tool for increasing awareness of one of the world's oldest diseases. The game was further supported through Microsoft's Academic Evangelist program and DeltaDNA's outreach activities to provide industry perspectives and expertise.

\section{Background}

Tuberculosis remains a global threat with more than nine million new infections every year (TB Alliance 2016, World Health Organization 2015). It is now the leading infectious disease cause of death, but is preventable if we had the tools and the will to eradicate it (Dye 2009; World Health Organization 2014). The disease is on the rise in many developed countries, where it was all but eradicated (Nebehay 2014), yet it is still largely regarded as a disease of the developing world. It is in the developing countries that the major burden of disease falls on the most productive age group. Thus, it is a disease of the poor and a disease that makes people even 
poorer. There is a stigma associated with the disease in some communities, which can result in some delay in attendance at health facilities. Many are unaware of the importance of tuberculosis and the threat to health that it poses to them, which may prevent individuals seeking care at a stage when their disease is more amenable to treatment. Where there is no facility for sick leave, paid or unpaid, many people delay consulting the health care system. Thus, the importance of seeking help for chronic cough or unintended weight loss is essential and attending a health facility rather than a traditional healer is important.

Conventional tuberculosis treatment remains difficult and there has been no significant change in the duration of the standard regimen since the early 1980s (Spigelman and Gillespie 2006). Moreover, many patients are unable to tolerate this treatment and discontinue therapy, increasing the risk of resistance (O'Neill 2014). Importantly, patients feel better long before it is safe for them to stop treatment, which can result in relapse of the disease and further damage to the lungs, or the risk of drug resistance developing. There is a growing tide of multiple drug resistance and few effective antibiotics to tackle the problem. Since the turn of the millennium there has been a surge in interest in developing new therapies for tuberculosis and a number of new drugs have been developed. Yet, these are insufficient and more research is required to ensure that we have enough new treatments and can understand how to deploy them, as clinical trials are expensive to perform (Gillespie et al. 2014; Merle et al. 2014).

There is a pressing need to explain the challenges of tuberculosis to a diverse group of audiences. Clinical research is essential, but expensive. Therefore, it is vital to communicate the importance to funding organizations, and the public that support them, to justify why it is necessary to make an increase in the funding to tuberculosis drug development. The market for anti-TB drugs is small, so there is little incentive for pharmaceutical companies to develop the required treatment (although many do through their corporate responsibility). This market failure means that tuberculosis research must be funded by the public purse and research on tuberculosis must compete with other worthy causes. Whether we like it or not, research into a disease competes for funding with other diseases: tuberculosis versus cancer versus malaria. If we are to increase the funding envelope for tuberculosis, the importance of the task must be made clear and that there is a route to a solution.

As tuberculosis is largely a disease of poverty and relatively uncommon in Europe in comparison with resource poor environments, there is a need to explain that research funding must be spent on a problem that is rare in Europe, but important globally. Even though we may argue that, in a global village, we all share infection problems, in reality diseases like tuberculosis are perceived to be distant and irrelevant. To address this challenge, we need to communicate to the wider population in an engaging way.

To be of value, tuberculosis research must be placed in the communities most in need of the solutions that the research may offer. Thus, before tuberculosis clinical research can start it is necessary to engage with local communities, explain the disease and the need for diagnosis and treatment, and the role that they may play in solving an important global problem. An important side effect would be to promote better health seeking behavior for tuberculosis and other diseases. Clinical research 
cannot and should never exist in an experimental vacuum; it must be placed in the context of a community. Thus, innovative educational tools could have an important role to play in achieving a permissive environment where research is possible because the community understands its significance and are empowered to test the assertions of researchers robustly.

Subjects of medical research often are required to participate in activities additional to their normal health care (Gillespie et al. 2014; Merle et al. 2012). It is more likely that patients will agree to this if they understand what they are giving to the wider community. We know from research that patients in trials have better outcomes than those not on trials irrespective of the disease in question. Thus, the better-informed patients are about their disease, the better their choice will be about whether they wish to participate.

Clinical research ethics require patients to give fully informed consent. Although there is considerable literature about the danger of potential conflicts of interest and unconscious inducements to participate, there is very little research that describes what background information potential subjects need to have before their decision is deemed informed. In some studies, potential subjects are given information and can only consent if they pass a test at the end that proves they understand the implications of their decision. Gaming may provide education without pain and it might be possible to embed in the game rules testing of essential principles that could confirm that potential subjects understood the nature of the trial, the benefits and the risks.

In a world where the mobile phone is everywhere, computer games provide a platform for communicating complex ideas and details in a digestible way. Much more can be communicated when the information is delivered in a "fun" environment (Singh 2014). Games that incorporate the facts of a disease and its treatment could have an important role to play. This has already been proven through games such as Foldit (2008) and Plague Inc. (Ndemic Creations 2012) Created by various departments and labs from the University of Washington, Foldit demonstrated that a game about folding protein strings could help crowdsource scientific solutions through gaming. In 2014 NDemic Creations galvanized their Plague Inc. community to help fundraise for charities that were working to fight the Ebola outbreak. Over 800,000 players visited the webpage and approximately $\$ 76,000$ was raised for charities such as the Red Cross, Disaster Emergency Committee and Médecins Sans Frontières. Other serious games that utilize crowdsourcing were a significant influence on the design of Sanitarium. Fraxinus (2013) is a game made to combat a specific species of fungus that was causing Ash Die Back in ash trees across Europe. The player uses real genetic data to try and find why some trees are immune to this fungus. Fraxinus demonstrated that it was possible to make a fun, entertaining game based on real scientific data. In particular, the gene matching puzzle showed that complex data could be presented in simple form and gameplay. Similarly, Play to Cure: Genes in Space (Guerrilla Tea 2014) funded by Cancer Research UK uses the collective force of players to analyze real genetic data. Ostensibly the game sees the player piloting a spaceship in order to collect Element Alpha. Underneath the surface the game finds the optimal route to pick up the most Element Alpha, and in doing so plots a course through genuine 
'DNA microarray' data. Crunching the data helps scientists identify the DNA faults that could lead to cancer. Other more specific TB games were, unbeknownst to the team, being developed at the same time and have subsequently been released. On World Tuberculosis Day, 24 March 2015, Tuberspot (2015) a serious game developed by researchers at the Polytechnic University of Madrid was released. In Tuberspot, players help analyze real digitized sputum samples and the overall aim is to develop a microscopy system on a mobile phone to allow telediagnosis. In 2016 a new version of the Eterna game from Stanford University was released. The initial version of Eterna was developed as a way to let citizen scientists design potentially useful biomolecules that are stable enough to function inside a living cell. Over the years, the players have become more and more expert in designing complex RNA molecules. The new version was developed with the aim of encouraging players to design a molecule that could help spur the development of a new tuberculosis test (Dushek 2016).

The collaboration for Project Sanitarium developed from the desire of the clinical team from the University of St Andrews to create a simple visual tool to present data from recent clinical trials (Gillespie et al. 2002, 2014; Honeyborne et al. 2011). At Abertay University, the School Arts, Media and Computer Games has established an interdisciplinary workplace-simulation model for students (Wenger 1998). The model groups students from across six degree programs (covering the disciplines of art, audio, code, design and production) into small teams. Each team is then assigned to a client brief and provided academic and industry mentors. The semester structure means that although the module is core for all the undergraduate programs it only accounts for a part of each student's academic workload. When looked at in contrast to professional development, the amount of time dedicated to all aspects of the project is approximately six weeks. Given the time constraints and the additional complications of working in a University environment (no dedicated workspaces, a completely flat team hierarchy, difficulty in bringing in additional resources and the restrictiveness of the academic calendar) the main goal for the students is to deliver a working prototype. The value of the model has been endorsed through various industry accreditation and academic reviews. From the academic perspective, industry-based interdisciplinary team projects help characterize the students learning experience and the situated practice ethos provide students with a portfolio of achievement. For industry, interdisciplinary workplace-simulation delivers a strong parallel with games industry practice and the requisite skills sought in prospective employees.

Although the workplace-simulation model fosters academic-industry collaborations, the development is not funded in any way and as a result success largely depends upon student commitment and engagement with the client and the project idea. The concept brought by the Infection Group demonstrated a clear opportunity and a suitable challenge to develop a game based around disease, but there was an inherent risk in persuading students to create a "fun" game about a deadly disease. In order to improve upon the project credentials, an initial concept was worked up to a more developed brief that settled on three core elements. These were to create a game that mimicked how the disease developed in a person, how treatments might be utilized to cure the disease and lastly to explore how new treatments might potentially work in the future. 


\section{Game development}

The aims were still broad and there remained a clear need to further define the audiences for the game and to consider how a game could remain "fun" but still engage with the serious subject matter. The project team embraced the challenge with a series of meetings to further define and develop the concept. It was through these sessions that new requirements and audiences were defined. It was established that the game needed to visually simplify multiple complex parameters for people developing new treatments for the disease. Features had to be developed to allow for exploring different patient symptoms, and how the virulence of the disease could be affected by different drug regimens or by designing and testing better treatments. There was additional discussion on the look and feel of the game. Whether the game should reflect the combat between the bug and the host and provide a quasi-realistic feel with images of the lungs, bacteria and human immune cells, or to take a more abstract consideration of the game aesthetics, mechanics and delivery. These meetings were essential to allow all parties the creative space to pitch ideas and respond to feedback. They also proved to set the tone for development through iterative 'sprints' rather than relying on designing everything upfront (Boehm and Turner 2003). The iterative nature of the development was largely feasible because the project was unfunded (there was no external or internal pressure to succeed) and success only required delivery of a prototype. Early mock-ups and rough code prototypes were presented through regular meetings and presentations, and through the frequent feedback each iteration on the core game became gradually stronger. One of the challenges of iterative development is that it can often be difficult to see progress. The team compensated for this by targeting several milestones each based around the delivery of a core feature. The result was the delivery of a prototype that delivered the project aims through focusing the core game on a mathematical model.

\section{Design overview}

The core game is a simulation based upon a mathematical model, although the model itself is completely hidden from the player. The model is used within the game to give an accurate portrayal of how TB will develop and grow within each patient's body. The game, as a reflection of the model, considers variables such as underlying health concerns, lifestyle choices, geographic locations, socio-economic considerations, or the impact of poor education. Variety in play is created by the interaction with the TB bacteria, which is used to provide a more unique experience for each player.

The design ethos was to rapidly prototype to deliver a polished experience. The emphasis on providing a high production value prototype was originally set out in a 2005 article (Gabler et al. 2005) and reignited in a talk at the Game Developer's Conference in 2012 (Jonasson and Purho). Polish, or as it is referred to in these articles and talks, juiciness, focused the game design on providing a richer player experience by adding different effects to improve the visual and auditory experience and overall feel of the game. The design aesthetics were therefore influenced by a 
variety of applications, games and films. Influence were taken from the visual style, layout and colors used in medical applications such as OsiriX (2016) to large industry productions like DICE's Mirrors Edge (Deadendthrills, n.d.), a game which uses colors to guide the player through the level. The Indie hit Papers Please helped influence how information is displayed (First Person Scholar 2013). Initial User Interface Designs were influenced by the clean design of Deus Ex (Behance.net 2011). That futuristic feel was further enhanced by research into cinematic blockbusters such as Iron Man (Pushing-Pixels.org 2014) to the new Star Trek reboots (Frei 2013). These influences led to the initial mock-ups and exploratory designs becoming the foundation of the look and feel of the game. The team also emphasized the importance of audio in the prototype to deliver a polished experience. The result was the audio team worked alongside the art team to ensure that the futuristic feel was delivered consistently through the content, deciding upon a clean electronic ambient soundtrack. The audio was also influenced by Hollywood: Iron Man, Gravity and Interstellar each encouraged the creation of music that would match the pace of the gameplay without overwhelming or creating audio fatigue in the player (Rosen 2013; Child 2014). However, it was the vision to bring in professional voice-over talent, Tara Platt, which helped to establish a clear audio identity (IMDb, n.d.). The steady pacing and clear scripting took the early prototypes to a different level and can be identified as the point that people started to take notice of the game.

Ostensibly the player takes on the role of a medical doctor throughout their career, from graduating medical school through to retirement. As a doctor the player navigates a variety of mini-games, each asking them to help in the diagnosis and treatment of patients. The more successful the player is, the more complex cases they get to diagnose and treat. The further the player advances, the more they travel to hotspots throughout the world, thereby encountering different parameters and different underlying variables. The player needs to take into consideration the patient history, such as the possibility of the patient being HIV positive, whether they smoke, drink, are overweight, or conversely suffer malnutrition. If the patient is uneducated, then there is a risk that they could stop treatments at the first sign of feeling better, thinking they are cured. This could result in relapse. The game also considers the economic difficulty the patients face in receiving treatment because they don't have the resources to be properly cared for. The recognition of the number of varying parameters and the importance of understanding how players would react to these led the team to incorporate game analytics software, provided by DeltaDNA. The inclusion of analytics enabled more effective playtesting.

\section{Mathematical modelling}

The game is underpinned by a mathematical model, which tracks the bacterial burden of patients throughout therapy. During tuberculosis treatment, sputum samples are taken at clinic visits and are tested to enumerate the bacterial load. This is the primary method of monitoring patient progress through therapy. This changing bacterial load in the sputum is what the mathematical model simulates. 
Mycobacterium tuberculosis can exist in several states: some bacteria are fast growing, and others grow more slowly or do not grow at all. Our mathematical model assumes two populations of bacteria, which we designate "fast-growing" and "slow-growing". Bacteria from each population can transfer between states as the bacteria change their condition according to local nutrient and oxygen levels. We model this mathematically by using two first-order ordinary differential equations, coupled through their transfer terms:

$$
\begin{aligned}
& \frac{d B_{f}}{d t}=g_{f} B_{f}-d_{f} B_{f}-t_{f s} B_{f}+t_{s f} B_{s} \\
& \frac{d B_{s}}{d t}=g_{s} B_{s}-d_{s} B_{s}+t_{f s} B_{f}-t_{s f} B_{s}
\end{aligned}
$$

$B_{f}$ and $B_{s}$ are the numbers of bacteria in the fast- and slow-growing bacterial populations, respectively. $g_{f}$ is the replication rate of the fast-growing bacteria, $g_{s}$ is the replication rate of the slow-growing bacteria, $d_{f}$ and $d_{s}$ are the death rates of the fast- and slow-growing bacteria, which capture the drug effect on the bacteria. Finally, transfer rates are specified in the equations, to allow the bacteria to change state during therapy, where $t_{f s}$ is the transfer rate from fast- to slow-growing bacteria and $t_{s f}$ is the transfer rate from slow- to fast-growing.

The sum of the two bacterial populations, $B_{f}+B_{s}$, is the total bacterial load in the sputum, which is tracked throughout the game to assess the player's performance.

To make the mathematical model and the players' input as realistic as possible we have made estimates for the various parameters underpinning the model from our clinical research and from the wider literature. To test whether the model resembled the normal management of tuberculosis, half of the data were used to constrain the parameters, with the other half being used to test the model results. Test simulations predicted that 30 out of the 48 patients would be below the limit of detection after 8 weeks of treatment; the actual number of patients with sputum samples below detection was 31 .

The parameters for the mathematical model are affected by individual patient stories inserted in the narrative of the game and the player's performance in the mini games is added to this. For example, the initial bacterial burden of a patient depends upon conditions such as whether or not the patient is a smoker. Since TB is a disease of the lungs, being a smoker will result in a higher initial count and it is recognized that patients who smoke have a poorer outcome in clinical trials. Other patient metrics can also affect the parameters of the model, for example if the patient is HIV positive, this can affect the lethality rates.

Within the prototype, the mini-games also affect the initial bacterial load and the lethality parameters within the mathematical model. If the player performs well in the diagnosis games, the baseline bacterial load decreases, representing the player having diagnosed the disease sooner. After this point, the initial number is divided into fast growing and slow growing populations. Based on previous in vitro laboratory experiments, the initial split is assumed to be 10\% fast growing and $90 \%$ slow growing. Finally, the Treatment game determines the values of the lethality 
parameters for the two populations, with a better performance resulting in higher lethality parameters, hence a shorter treatment time.

As the game is developed in future, new mini-games will affect different aspects of patient treatment and the mathematical model. The player gaining access to new equipment and different drug regimens will also have an impact on these parameters.

\section{Main game}

The core of the game centers round the player looping through four event screens: Doctor, World Map, Patient and Diagnosis/Treatment (Fig. 1). The Doctor screen provides all the player-specific information regarding their status within the game world. This includes personal and medical information, plus game events that may impact upon player actions. From there the player can decide to enter either the World Map or the Patient screens. In the World Map, various cases or geographical hotspots can be selected (Fig. 2). On selecting a location, the player is presented with patient information and can make the decision to treat the patient or return to the map if they don't feel confident about that particular case. Underneath the surface of this the game uses the mathematical model to determine a patients' profile (weight, smoker, non-smoker, geography, etc.).

The patients' profile will then affect the difficulty level of the diagnosis minigames. Once the player does select to treat the patient they move to the Patient screen (Fig. 3). Here, they select a mini-game from a variety of options and progress to play that game. The player succeeds by correctly diagnosing then managing to cure each patient, adding to their overall score. Once the player reaches the end of their career cycle (i.e. retirement), the score is totaled and displayed upon online leaderboards. Since the game features a rogue-like element, each play through will present different challenges and patients. This in turn will mean that players can play through the game multiple times, each time encountering different scenarios and outcomes. Most importantly, difficulty will be altered based upon the player's success each time around.

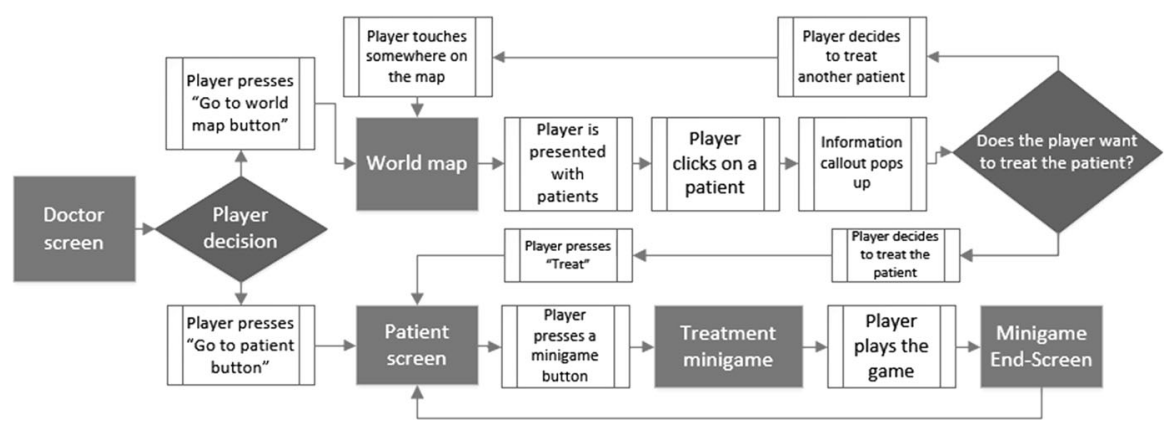

Fig. 1 Main game loop 


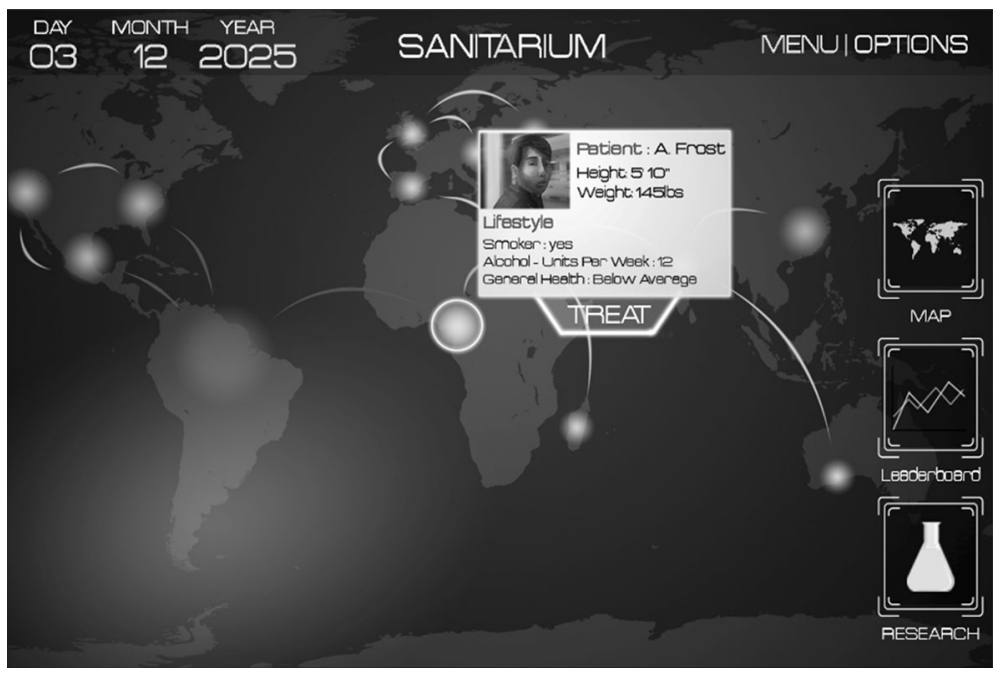

Fig. 2 The world map
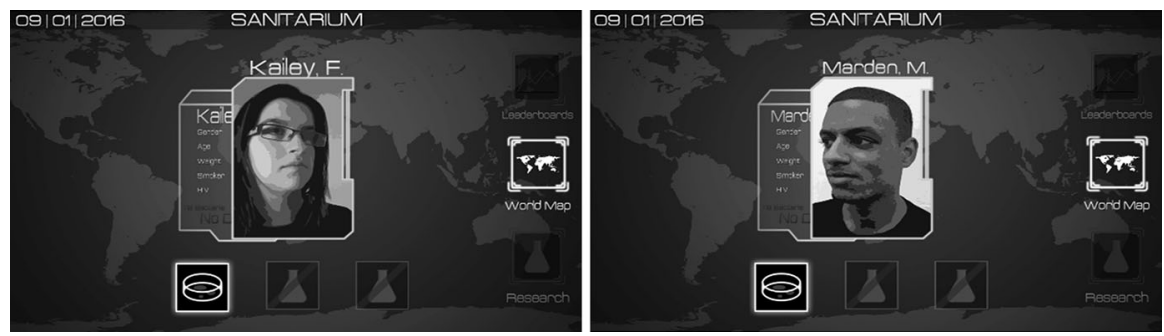

Fig. 3 Patient screens

\section{Mini-games}

In the game world, the procedures of patient diagnosis and treatment are represented and implemented as mini-games, each representing a diagnosis test and a corresponding treatment. The outcome of playing each determines the condition of the patient and the possible result of their treatment. All of the mini-games factor into the final score for each patient, and whether the player is able to cure them. The design aim here was to provide a quasi-realistic game environment for the player and to provide some gameplay variety. The prototype developed three mini-games, with the intention of expanding this if the project went forward. For the purposes of the prototype development, the mini-game design represents a simplified three-step process in diagnosis and treatment. The first step being a smear test, the second, an $\mathrm{X}$-ray, and third the prescription of some form of drug treatment (National Health Service 2016, Wang and Oshi 2014). The intention was to provide these initial games at a high level of polish and to add more mini-games if time and resources allowed. 
The first mini-game developed represented a Petri dish, where the player is required to identify and kill TB bacteria (Fig. 4). In the mini-game the player is presented with a petri dish with various cells around the scene. They then rotate around the petri dish and count bacteria by shooting them within a specific time frame. This represents a sputum test where a doctor will take a saliva swab then count the bacteria from the swab in the petri dish. The design also identified that there are 'good bacteria' and for every good bacteria the player hits they lose one second on the timer. It builds upon a game mechanic that combined arcade classics such Whac-A-Mole and Space Invaders before evolving through play testing to the current version (Sellers 2001).

The second diagnosis mini-game is the X-ray game (Fig. 5), and proved challenging due to the difficulty in accurately representing real-world diagnosis. The aim of this was to get the player to identify problems within the patient's lung. The player has a limited number of guesses within a defined time frame to spot and identify the cavities within the lung X-ray. Although simplistic, the game is fundamentally more realistic and educational than the other mini-games. Reading $\mathrm{X}$-rays is challenging and requires considerable training for clinical staff. The design of the game is based on real software OsiriX (2016), which medical professionals use to examine X-rays. This allows the player to adjust the brightness and contrast of the image to facilitate the identification of cavities. The player's performance in the Petri dish and X-ray games determine the initial total number of bacteria: a poorer performance in the games results in the patient being infected with TB for longer before detection, and hence a higher initial number of bacteria.

The final mini-game for the prototype represented treatment (Fig. 6). To that end a Breakout style game was created to mimic various drug regimens (Kent 2001). The mini-game uses data from the previous two games to determine the initial layout and difficulty. The player controls a paddle and must reflect the pill (the ball) into the blocks which represent the TB bacteria. The player has one ball that can change into four different colors, each color representing one of the different drugs in the treatment. Each colored ball has a countdown timer that starts and stops when

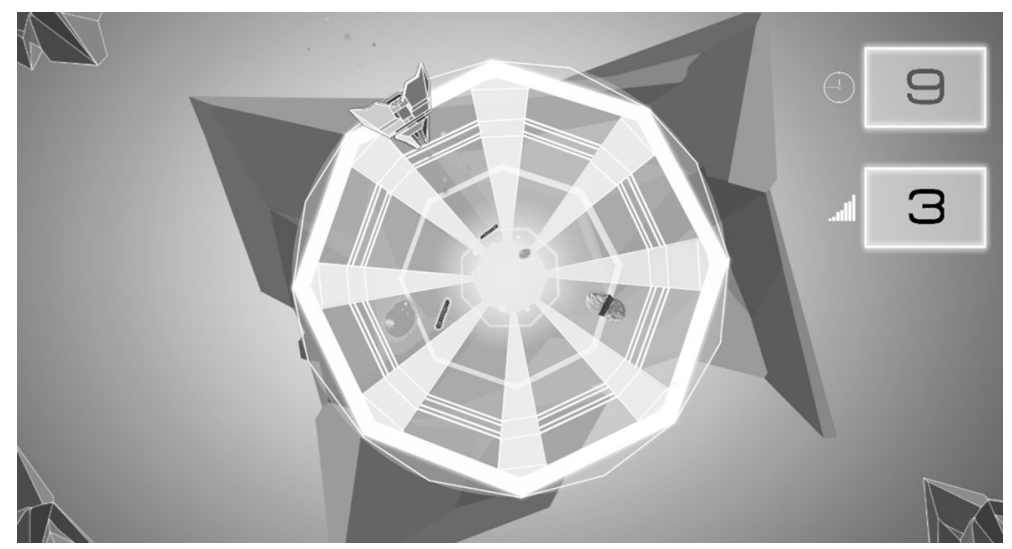

Fig. 4 Petri dish mini-game 


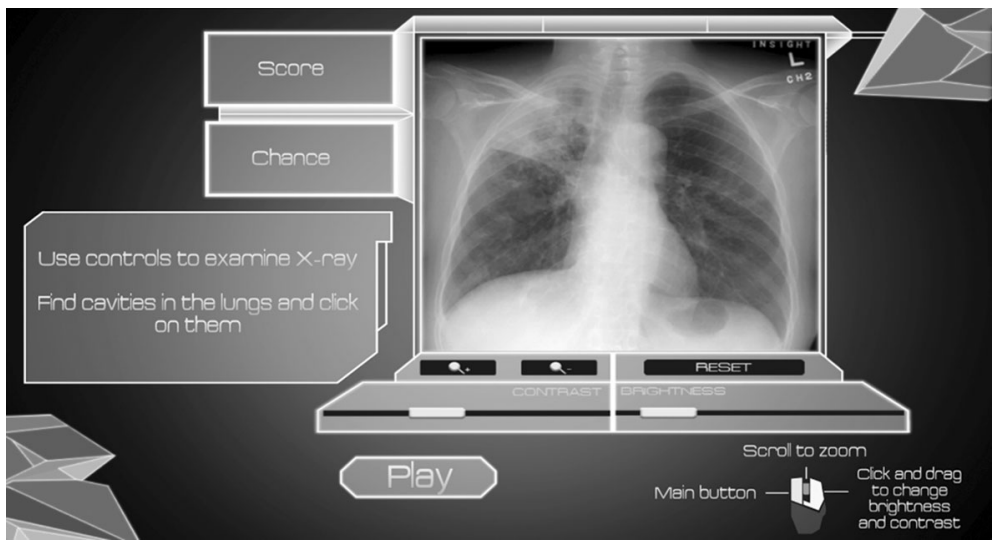

Fig. 5 X-ray mini-game

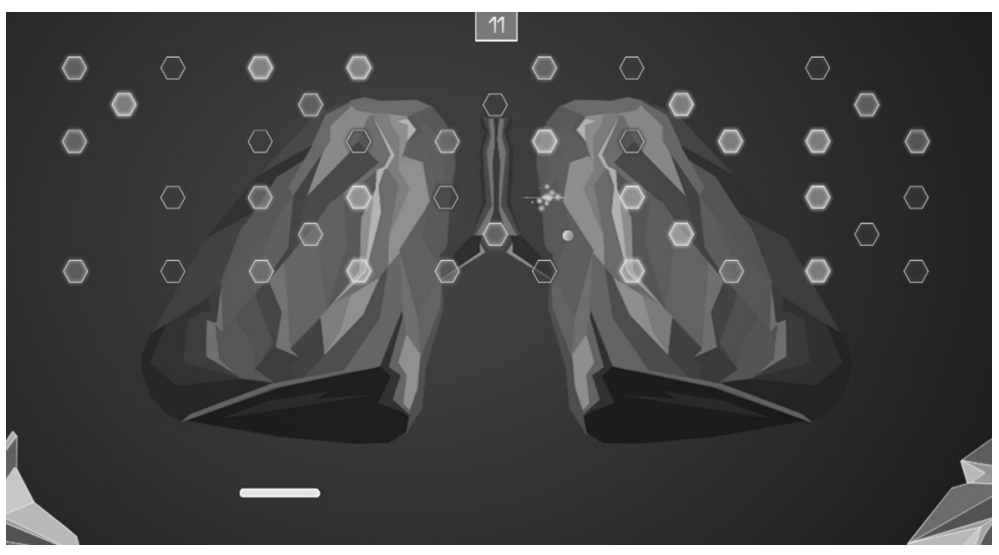

Fig. 6 Treatment mini-game

that color is selected or deselected. This mimics the time sensitive nature of the effectiveness of each drug as in the real world. The colored balls are used to destroy the corresponding colored blocks, with the score being determined by how many blocks the player destroys and how many are left intact. Multiple restart and powerup opportunities are provided, and again player success has a direct impact upon the virtual patient's health by determining the lethality parameters within the mathematical model. A better performance in the mini game results in higher lethality rates and hence faster treatment. Essentially success in the mini-games increases the chances of progression in the overall game. Although not implemented for the prototype, each successful treatment results in additional time and monetary resource. Effective management of the resources and making difficult moral decisions then affect the overall game progression. 


\section{Game analytics}

Given the complexity of the differing parameters and the impact that the mathematical model (and each mini-game) could have on the wider game it was decided early on to utilize game analytics to aid with the design and iteration. Again, the nature of prototype development encouraged the adoption of commercial tools by established game analytics provider DeltaDNA (2017) and those provided through Microsoft's cloud computing platform Azure. The use of analytics in games is a relatively recent development and largely driven by the Free-To-Play (F2P) and social marketplace. Game analytics services such as DeltaDNA provide the means for data collection, viewing and analysis. Although heavily focused towards understanding player behavior for commercial gain, the ability to use core measurements and define custom events can be used to understand wider player behaviors and allow the project team to understand where player behavior deviates or mimics behavior demonstrated from clinical trials. The game can then record or compensate for differing behaviors. Implementation of game analytics in the development process enables the team to gain a low level understanding of players interactions with the game which, when combined with further quantitative research, provides deeper insight into potential problems and solutions. The team determined that for game to effectively utilize the mathematical model, the prototype needed to track all the original patient variables and how each was impacted by playing the mini-games. The generated data for parameters such as smoker status, HIV status, age, weight, gender, wealth, location and occupation could then be used and the model simulations utilized to find links and correlations between certain circumstances and the effects on the patients TB status. The key analytics for proof of concept were identified as player engagement and stickiness.

\section{Results}

The game prototype of Project Sanitarium was made available through download via the web in summer 2015. Since then the project team have attended events, presented at various games shows and delivered talks about the project with the aim of slowly growing the user base and making incremental gameplay improvements based on the analytics gathered. The prototype phase moved into an evaluation phase. The prototype demonstrated that the initial objectives set out in the brief could be achieved. Namely that a game could simulate the experience of clinical trials in a fun and informative way, and more fundamentally that the mathematical model could be modified and adapted based upon the data collected.

Using the data collection regarding player engagement and retention from April 2015 to end of December and correlating the data with events and social media campaigns demonstrated that the game had some success in achieving the original aims (see Fig. 7.). Analyzing the number of installs and tracking the number of active users demonstrated that attending events and talking about the project was necessary in generating interest in downloading the game, and that there was considerable drop off of active players as time progressed. This was entirely 


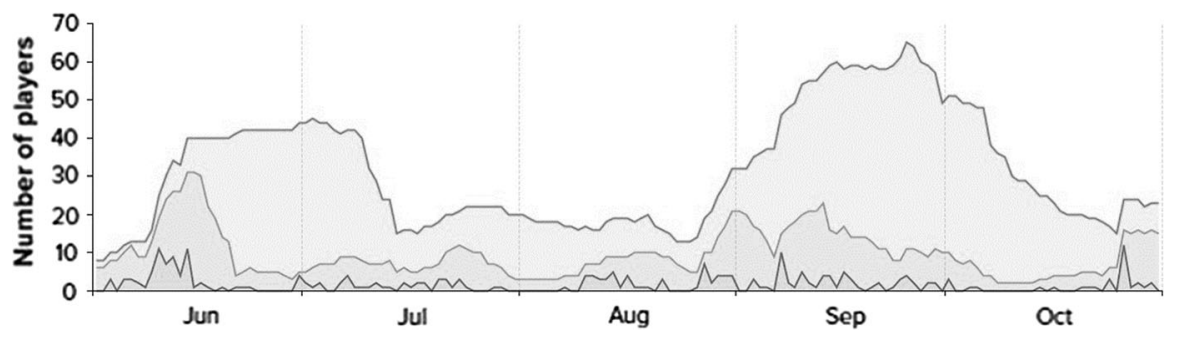

Fig. 7 User engagement. Upper curve monthly players, middle curve weekly players, lower curve daily players

expected as the game prototype was significantly limited in scope and without new content and additional development players would naturally drop off. In each of the player engagement measurements the team witnessed spikes that directly correlated with the game and public engagement. Competition success, demo events and associated press coverage proved to be the most effective means of encouraging new players. Without any marketing budget this was also the most cost-effective. Overall the game attracted over 500 players and using the analytics it was possible to track their largely similar user journeys. The data demonstrated that players initially engaged in longer play sessions and, by tracking in-game events, showed that players would generally play through the patient lifecycle. Players understandably wanted to see not only how the disease developed in a person, but how treatments might be utilized to cure the disease. The aim of educating players about the threat of tuberculosis was enhanced by the fact that player sessions were representative of the patient lifecycle. However, it was also clear that player retention (players returning to play the game) was always going to be limited. Indeed, the percentage of players still playing was measured after one, seven, fourteen and thirty days and the retention is calculated by looking at players that played on a specific date and then returning. Once internal testing was removed from the analysis it was apparent that the prototype did not deliver player retention, but this was largely expected due to the lack of a fully featured product and limited game content. The team was initially buoyed by the stickiness measurement of the game.

Stickiness is defined as the ratio of daily or monthly active users returning and engaging with the game. If the stickiness is low then there are higher numbers of new players active in the game whereas if the stickiness is high then there are higher proportions of returning players currently active. However, it was quickly apparent that these numbers were unreliable. Stickiness proved too difficult to analyze and trust, due to internal testing and they were skewed further by using the same demo hardware at events (see Fig. 8).

The uptake of players and the fact that play sessions were generally covering the patient lifecycle also ensured that the analytics could track in-game events. The majority of the tracked parameters were used help improve the design of the overall game. Without the analytics we would have had to rely on less quantitative data through questioners on focus testing. The analytics enabled us to identify key issues, 


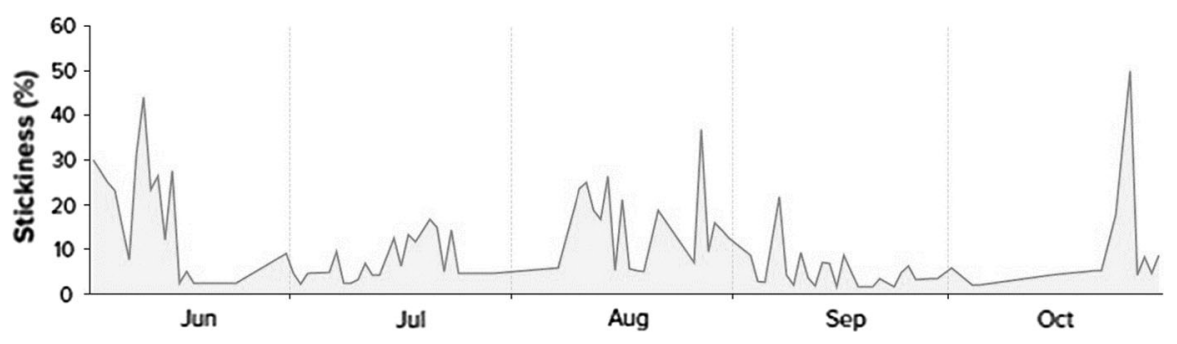

Fig. 8 Stickiness

such as players not understanding game elements or where to go. The event parameters were also useful in providing information back to the Infection Group should they want to adapt the current mathematical model presented in the game. However, it was also clear that further iteration on the model would require a more complete game. What the analytics indicated was that the prototype had potential, but more importantly that analytics would prove to be vital in providing a large amount of useful player information: player numbers, returning players, stickiness, how long players spend on different parts of the game, how difficult players found specific mini-games. In a full game these would in turn affect further development, informing updates of the game and impacting on the future design iteration for both players and academics utilizing the data.

In order to determine the success of the project, the best indicator beyond the analytics was the plaudits the game secured through entering competitions and the press coverage. The completed prototype earned the team a place in the Games category for UK Finals of Microsoft's the Imagine Cup. The game also placed third in the Microsoft Azure Gaming Innovation challenge, was selected as a finalist in the Game with a Purpose category at the TIGA Games Industry awards and won a Gold award at the 2015 International Serious Play Awards (2015). Press coverage was also favorable and started with an exclusive look on BBC Two's Scotland 2015 program and the BBC News website (MacDonald 2015). The game was featured on both the Scotland and Technology pages. This was then followed by broadcasts on other local media channels such as STV, Radio Tay and Wave 102; game websites such as Destructoid (Parlock 2015) and Rock Paper Shotgun (Gera 2015); and international coverage in countries such as India where TB remains prevalent (Zee News 2015), Spain (Escandell 2015) and Turkey (Zaman 2015). Other sources that picked up the story include The Scotsman, Engineering and Technology Magazine (Gent 2015), University Business (Paddick 2015) and Yahoo! News. Certainly the coverage and limited success demonstrated that prototype had potential, but it was also clear that the game needed more development. The team had achieved considerable success, but could not continue development indefinitely. A hard decision was made to maintain the project and limit development to small incremental changes while investment was sought. 


\section{Conclusion}

The Project Sanitarium prototype proved to be a successful academic-industry collaboration. The core educational aim of using a workplace simulation model to instruct students was enhanced by the success of a project that encouraged both personal growth through public engagement and collaboration with other institutions, industry partners and disciplines. The team proved that ambition could be a significant motivator, whilst the prototype has its limitations the foundations were laid for further research to establish the use of games to simulate a virtual clinical trial. If realized, such crowdsourcing could reduce the extensive costs of trials and enable researchers to focus on a limited set of potential solutions.

Project Sanitarium is furthermore an attempt to inspire new audiences to become more tuberculosis-aware, science-literate and to bridge the gap between learning abstract science 'concepts' and actually 'playing' with science through simulation. The project demonstrates the potential that serious games can have in delivering as both an educational experience and in raising awareness about complex topics. The game prototype, whilst enjoying some success in competitions and in generating media interest, also demonstrates what can be achieved with an undergraduate team and without project specific funding. For the undergraduate team to take on the challenges of developing and delivering a game that addresses the fundamental aspects of diagnosing and treating tuberculosis in the modern day, whilst remaining true to an underlying mathematical model, and still provide an experience entertaining enough to enjoy both industry and press recognition is a success for all of the team to be proud of. The project further demonstrates that serious games research and development provide unparalleled opportunities for raising awareness. However, for the project to progress to a fully-fledged product there is a need for further development and iteration. All the indications are that the potential could be realized but that success remains dependent on securing additional funding.

Acknowledgements The authors would like to thank the Abertay students, Microsoft UK's Technical Evangelist Lee Stott, Chief Technical Officer Chris Wright and the team at DeltaDNA, and the entire Infection Group at the University of St Andrews for all their help and support in making the project possible. The prototype is available for download at http://radicationgames.com/ and videos are available on the Radication Games YouTube channel at https://www.youtube.com/channel/UCeooLt5T6aC8xgac MHo5ceQ.

\section{Compliance with ethical standards}

Conflict of interest The authors declare that they have no conflict of interest.

Open Access This article is distributed under the terms of the Creative Commons Attribution 4.0 International License (http://creativecommons.org/licenses/by/4.0/), which permits unrestricted use, distribution, and reproduction in any medium, provided you give appropriate credit to the original author(s) and the source, provide a link to the Creative Commons license, and indicate if changes were made. 


\section{References}

Behance.net. (2011). Deus ex human revolution-User interface. Retrieved from https://www.behance. net/gallery/2465641/Deus-Ex-Human-Revolution-User-Interface. Accessed August 30, 2016.

Boehm, B., \& Turner, R. (2003). Balancing agility and discipline: A guide for the perplexed. Boston, MA: Addison-Wesley Longman Publishing Co., Inc.

Child, B. (2014). Interstellar's sound 'right for an experimental film', says Nolan. The Guardian. Retrieved from: http://www.theguardian.com/film/2014/nov/17/interstellar-sound-christopher-nolan. Accessed August 30, 2016.

Deadendthrills. (no date). Building the impossible: The art of mirror's edge. Retrieved from http:// deadendthrills.com/building-the-impossible-mirrors-edge/. Accessed August 30, 2016.

DeltaDNA. (2017). https://deltadna.com/.

Dushek, J. (2016). Researchers release video game to help build a better test for tuberculosis. Stanford Medicine News Center. https://med.stanford.edu/news/all-news/2016/05/researchers-release-videogame-to-help-build-better-tb-test.html. Accessed August 30, 2016.

Dye, C. (2009). Doomsday postponed? Preventing and reversing epidemics of drug-resistant tuberculosis. Nature Reviews Microbiology, 7, 81-87.

Escandell, D. (2015). Project Sanitarium quiere concienciar sobre la tuberculosis. Vandal. Retrieved from http://www.vandal.net/noticia/1350668116/project-sanitarium-quiere-concienciar-sobre-latuberculosis/. Accessed August 30, 2016.

First Person Scholar. (2013). The art of papers, please. Retrieved from: http://www.firstpersonscholar. com/the-art-of-papers-please/. Accessed August 30, 2016.

Foldit: Solve Puzzles for Science. (2008). https://fold.it/portal/. Accessed August 30, 2016.

Frei, V. (2013). Interview-Star trek into darkness: Roger Guyett. Retrieved from http://www.artofvfx. com/?p=4623. Accessed August 30, 2016.

Gabler, K., Gray, K., Kucic, M., \& Shodhan, S. (2005). How to prototype a game in under 7 days: Tips and tricks from 4 grad students who made over 50 games in 1 semester. Gamasutra. Retrieved from http://www.gamasutra.com/features/20051026/gabler_01.shtml. Accessed August 30, 2016.

Gent, E. (2015). Videogame created to test model of tuberculosis spread. Engineering \& Technology Magazine. Retrieved from http://eandt.theiet.org/news/2015/aug/sanitarium-game.cfm. Accessed August 30, 2016.

Gera, E. (2015). Sanitarium: A game that hopes to cure tuberculosis. Rock Paper Shotgun. Retrieved from https://www.rockpapershotgun.com/2015/09/07/project-sanitarium-tuberculosis-game/. Accessed August $30,2016$.

Gillespie, S. H., Crook, A. M., McHugh, T. D., et al. (2014). Four-month moxifloxacin-based regimens for drug-sensitive tuberculosis. New England Journal of Medcine, 371, 1577-1587.

Gillespie, S. H., Gosling, R. D., \& Charalambous, B. M. (2002). A reiterative method for calculating the early bactericidal activity of antituberculosis drugs. American Journal of Respiratory and Critical Care Medicine, 166(1), 31-35.

Guerrilla Tea. (2014). Play to cure. Retrieved from http://www.guerillatea.com/play-to-cure-genes-inspace/. Accessed August 30, 2016.

Hesseling, A. C., Walzl, G., Enarson, D. A., et al. (2012). Baseline sputum time to detection predicts month two culture conversion and relapse in non-HIV-infected patients. The International Journal of Tuberculosis and Lung Disease, 14(5), 560-570.

Honeyborne, I., McHugh, T. D., Phillips, P. P. J., et al. (2011). Molecular bacterial load assay, a culturefree biomarker for rapid and accurate quantification of sputum mycobacterium tuberculosis bacillary load during treatment. Journal of Clinical Microbiology, 49, 3905-3911.

IMDb. (no date). Tara Platt. Retrieved from http://www.imdb.com/name/nm1297428/. Accessed August $30,2016$.

Jonasson, M., \& Purho, P. (2012). Juice it or lose it. Retrieved from https://www.youtube.com/watch?v= Fy0aCDmgnxg. Accessed August 30, 2016.

Kent, S. (2001). Ultimate history of video games. New York: Three Rivers Press.

Macdonald, K. (2015). The digital game that could cure TB. BBC News. Retrieved from http://www.bbc. co.uk/news/uk-scotland-34070135. Accessed August 30, 2016.

Merle, C. S., Fielding, K., Sow, O. B., et al. (2014). A four-month gatifloxacin-containing regimen for treating tuberculosis. New England Journal of Medicine, 371, 1588-1598. 
Merle, C. S., Sismanidis, C., Sow, O. B., et al. (2012). A pivotal registration phase III, multicenter, randomized tuberculosis controlled trial: Design issues and lessons learnt from the Gatifloxacin for TB (OFLOTUB) project. Trials, 13, 61.

National Health Service (NHS). (2016). Tuberculosis (TB). Retrieved from http://www.nhs.uk/ Conditions/Tuberculosis/Pages/Introduction.aspx. Accessed August 30, 2016.

Ndemic Creations. (2012). Plague Inc. http://www.ndemiccreations.com/en/22-plague-inc. Accessed August 30, 2016.

Nebehay, S. (2014). Target tuberculosis in rich world as model for poor: WHO. Retrieved from http:// www.reuters.com/article/us-health-tuberculosis-idUSKBN0F816Q20140703. Accessed August 30, 2016.

O'Neill, J. (2014). Antimicrobial resistance: Tackling a crisis for the health and wealth of nations. The Review on Antimicrobial Resistance. Retrieved from http://www.jpiamr.eu/wp-content/uploads/ 2014/12/AMR-Review-Paper-Tackling-a-crisis-for-the-health-and-wealth-of-nations_1-2.pdf. Accessed August 30, 2016.

OsiriX. (2016). http://www.osirix-viewer.com/index.html. Accessed August 30, 2016.

Paddick, R. (2015). TB video game battles world's oldest disease. University Business. Retrieved from http://universitybusiness.co.uk/Article/tb-video-game-battles-worlds-oldest-disease. Accessed August $30,2016$.

Parlock, J. (2015). Sanitarium is a game that might help treat tuberculosis in the real world. Destructoid. Retrieved from https://www.destructoid.com/sanitarium-is-a-game-that-might-help-treat-tuberculosisin-the-real-world-308968.phtml. Accessed August 30, 2016.

Pushing-Pixels.org. (2014). At the intersection of the physical and digital-interview with Michael Goldman. Retrieved from http://www.pushing-pixels.org/2014/06/24/at-the-intersection-of-thephysical-and-digital-interview-with-michael-goldman.html. Accessed August 30, 2016.

Rosen, C. (2013). Gravity' composer Steven price on the film's incredible soundtrack. The Huffington Post. Retrieved from http://www.huffingtonpost.com/2013/10/04/gravity-steven-price_n_4039455. html. Accessed August 30, 2016.

Sellers, J. (2001). Arcade fever: The fan's guide to the golden age of video games. Philadelphia: Running Press.

Serious Play Awards. (2015). http://seriousplayconf.com/2015-serious-play-awards/. Accessed August $30,2016$.

Singh, A. (2014). Games to combat tuberculosis. International Journal of Science and Research, 3(1), 361-367.

Spigelman, M., \& Gillespie, S. (2006). Tuberculosis drug development pipeline: progress and hope. The Lancet, 367, 945-947.

TB Alliance. (2016). Our mission. Retrieved from http://www.tballiance.org/about/mission.php. Accessed August 30, 2016.

Team Cooper. (2013). Fraxinus. http://teamcooper.co.uk/work/fraxinus/. Accessed August 30, 2016.

Tuberspot. (2015). http://tuberspot.org/en/. Accessed August 30, 2016.

Wang, M., \& Oshi, R. (2014). Working paper: Benefits and costs of the tuberculosis targets for the post2015 development agenda. Copenhagen Consensus Center. Retrieved from http://www. copenhagenconsensus.com/sites/default/files/health_viewpoint_tb_-_wang.pdf. Accessed August $30,2016$.

Wenger, E. (1998). Communities of practice: Learning, meaning, and identity. New York: Cambridge University Press.

World Health Organization. (2014). Global tuberculosis report. Geneva.

World Health Organization. (2015). Tuberculosis fact sheet. Retrieved from http://www.who.int/ mediacentre/factsheets/fs104/en/. Accessed March 30, 2015.

Zaman, K. (2015). Ви оуипи oynayarak Tüberküloz hastalı̆̆ının tedavisine katkıda bulunabilirsiniz!. Level. Retrieved from http://www.level.com.tr/haber/genel/bu-oyunu-oynayarak-tuberkuloz-hastaliginintedavisine-katkida-bulunabilirsiniz.html. Accessed August 30, 2016.

Zee News. (2015). New video game battles tuberculosis. Zee News. Retrieved from http://zeenews.india. com/news/health/health-news/new-video-game-battles-tuberculosis_1665180.html. Accessed January $14,2016$. 
Iain Donald is a Lecturer in Interactive Media Production at Abertay University. He enjoyed a career in IT and Game Development before coming to teaching in 2010 when he joined the School of Arts, Media and Computer Games. His principal research interests lie exploring the value of serious games and the intersection of games, digital media, and history.

Karen A. Meyer is a Lecturer in Applied Mathematics and researcher in Solar Physics at Abertay University. Her research mainly focuses on numerical simulations and observations of the Sun's magnetic field, but she also has an interest in real-time physics simulations for games, as well as games as a platform for outreach and education.

John Brengman was Team Leader of Radication Games. An excellent audio engineer and producer, he had hoped to establish Radication Games as an independent games studio after graduating. Sadly, he passed away in December 2016. He is fondly remembered by all those that knew and worked with him.

Stephen H. Gillespie was appointed to the Foundation Sir James Black Chair of Medicine at the University of St Andrews in August 2010. He had previously been the Professor of Medical Microbiology at University College London at the Royal Free Campus. He has worked on the development of new treatments for tuberculosis for more than 25 years. He has recently completed the REMoxTB clinical trial, the first regulatory study of a novel treatment shortening regimen. He now leads the STAND trial seeking to provide a four month regimen for both susceptible and resistant disease. He also leads the European African PanACEA and PANBIOME consortia seeking to find shorter treatments and better diagnostics.

Ruth Bowness is a research fellow in mathematics, working as part of the Infection group in the School of Medicine. Her current research involves using partial and ordinary differential equations, and individual-based models to describe tuberculosis bacteria during an infection. She also uses statistical modelling techniques to describe clinical trial and laboratory data. 